\title{
CÁlCULO DO CUSTO DAS ATIVIDADES DE GESTÃo AMBIENTAL: APLICAÇÃO DO CUSTEIO BASEADO EM ATIVIDADES NUMA MONTADORA DE ÔNIBUS
}

\section{ENVIRONMENTAL MANAGEMENT COST CALCULATION: ACTIVITY BASED COSTING APPLIED TO BUS ASSEMBLY PROCESS}

\author{
Orlando Durán ${ }^{1} \quad$ Jorge Telles $^{2} \quad$ Liziane Lanza $^{2}$ \\ Recibido 20 de septiembre de 2005, aceptado 10 de enero de 2007 \\ Received: September 20, 2005 Accepted: January 10, 2007
}

\begin{abstract}
RESUMO
Este trabalho apresenta os resultados da aplicação da metodologia de custeio baseado em atividades para medir o impacto que as atividades de gestão ambiental podem ter no custo industrial dos produtos. Um estudo de caso é apresentado junto com a utilização de um software comercial para o cálculo dos custos.

Palavras chave: Custos baseados em atividades, gestão ambiental.
\end{abstract}

ABSTRACT

This manuscript presents an Activity Based Costing application in an environmental protection context. The aim of this work is measuring the impact of environmental management activities on product costs. Also, a case study is discussed and the utilization of commercial software is presented.

Keywords: Activity based costing, environmental management.

\section{INTRODUÇÃO}

Os Custos Ambientais são representados pelo somatório de todas as despesas e dos recursos utilizados pelas atividades desenvolvidas com o propósito de controle e recuperação ambiental [16]. O termo custo ambiental, segundo [1], ainda hoje, é um termo de difícil conceituação, pois a literatura não apresenta uma definição clara e objetiva do que se considera como um custo ambiental. A primeira dificuldade que se encontra ao se trabalhar com custo ambiental, é o próprio fato de serem estes, em sua maioria, custos intangíveis e/ou externalidades. O reconhecimento dos custos ambientais, e seu correto tratamento, permitem a obtenção de resultados mais próximos da realidade e um melhor gerenciamento ambiental das operações. Isso pode ser obtido através da internalização desses custos e, portanto, em menores impactos ao meio ambiente e para a sociedade, uma vez que quando a empresa não assume um papel pró-ativo em relação ao meio ambiente, a sociedade arcará com os efeitos. Um resultado mais próximo da realidade espelha o efetivo desempenho ambiental da empresa em cada período, bem como o reflexo da atuação dos gestores em relação à questão ambiental [16]. A questão da apropriação adequada dos custos ambientais torna-se crucial na medida em que estes custos têm aumentado significativamente nos últimos tempos. Isso decorre de uma legislação ambiental mais severa, tanto a nível nacional, quanto internacional, bem como do aumento na consciência e cobrança de parte dos clientes.

A partir da correta apropriação destes custos diversas ações poderão ser encaminhadas pelos gestores apontando a menores impactos e maiores benefícios econômicos e de imagem para a organização. Podemos citar, por exemplo, o controle de insumos antipoluentes, bem como a redução dos detritos originados por um dado processo industrial, com o conseqüente impacto que isto poderá causar nos custos de um produto e na sua lucratividade. Tradicionalmente, os custos ambientais, têm sido tratados como custos indiretos, os chamados "overheads". Como tais, estes custos não são apropriados ou alocados a

\footnotetext{
1 Escuela de Ingeniería Mecánica. Pontificia Universidad Católica de Valparaíso. Valparaíso, Chile. E-mail: orlando.duran@ucv.cl

2 FEAR. Universidade de Passo Fundo. Campus Bairro São José. Passo Fundo, RS, Brasil.
} 
determinados processos, produtos ou instalações, mas são tratados, geralmente de uma das seguintes formas:

1. Custos são alocados baseando-se em algum critério de rateio aos produtos.

2. São acumulados num grupo de custos, e tratados como custos fixos ou despesas.

Se os custos indiretos são alocados incorretamente, um dado produto poderá receber uma parcela maior do que a correspondente parcela de custos indiretos, enquanto que outro produto poderá estar recebendo uma parcela menor, produzindo desequilíbrios que afetarão o processo de tomada de decisões. Esse desequilíbrio prejudicará, por exemplo, a correta definição de preços dos produtos e a sua lucratividade, acarretando a falta de subsídios corretos para o encaminhamento de ações que reduzam os custos ligados à gestão ambiental como um todo.

Pode-se ilustrar esta situação através de um simples exemplo [8]. Observe na figura 1, um sistema tradicional de custos, onde os custos ambientais e outros custos indiretos são alocados aos produtos usando como base de rateio, por exemplo, o consumo da Mão de Obra Direta (MOD) ou a Matéria Prima (MP). Suponha ainda que o produto B é causador exclusivo dos efluentes tratados na empresa, ou seja é um produto "sujo". O sistema tradicional de custeio irá gerar desequilíbrio na apropriação dos custos ambientais, posto que, uma parcela desses irá ser carregada nos produtos $\mathrm{A}$, sendo que esses produtos não geram detritos de nenhuma espécie. A linha segmentada apresenta uma forma mais adequada de tratamento dos custos ambientais, apropriando-os apenas aos produtos B. Isto é feito através da extração do conjunto de custos indiretos de todos os custos relacionados com o tratamento de efluentes. Assim esses custos passarão a ser direcionados somente aos produtos do tipo B.

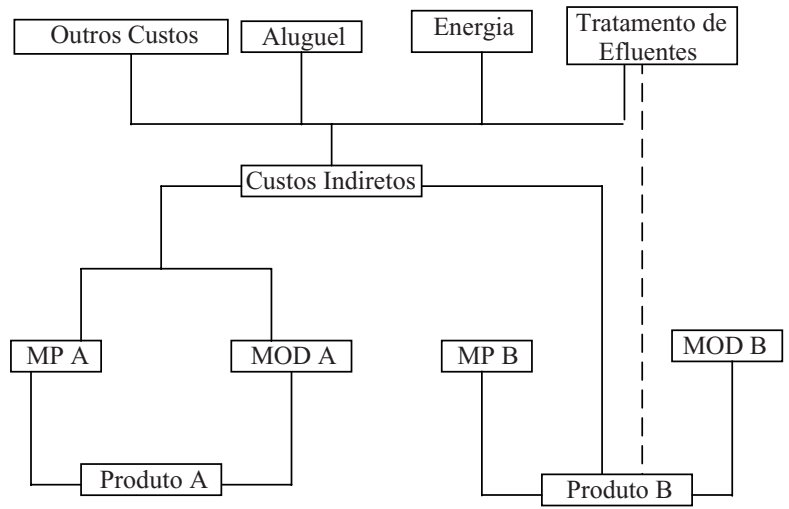

Figura 1. Tratamentos alternativos dos custos do Tratamento de Efluentes.
Este artigo visa apresentar uma aplicação real do cálculo de custos ambientais e suas apropriações em uma área de tratamento de efluentes numa empresa montadora de carrocerias utilizando a metodologia de custeio baseado em atividades. Na próxima seção são comentados alguns aspectos do sistema em estudo, para posteriormente mostrar os detalhes do modelo aplicado. Finalmente, na seção de conclusão serão comentados aspectos relevantes da metodologia e se apresentam os encaminhamentos necessários para ampliar a aplicação da mesma metodologia em outras áreas da empresa.

\section{CUSTOS AMBIENTAIS SOB UM ENFOQUE BASEADO EM ATIVIDADES}

O Sistema de Custos baseados em Atividade (ABC) surge na década de oitenta como uma tentativa de solucionar a grande dificuldade de apropriar os custos indiretos aos produtos [10]. Hoje em dia as aplicações baseadas nesta metodologia abrangem diversos setores da indústria, tanto em industrias de manufatura como de produção de serviços $[18,12]$ e podem ser encontradas aplicações em empresas dos mais diversos tamanhos $[6,9]$.

Tradicionalmente apropriados usando taxas, os custos indiretos eram lançados aos produtos usando critérios subjetivos e imprecisos. Esta situação, apesar de ter sido diagnosticada muitos anos antes, não tinha sido tratada com profundidade posto, que tradicionalmente os custos indiretos não conformavam uma parte significativa dos custos totais dos produtos. Isto pode ser considerado como uma herança da era onde os sistemas produtivos eram intensivos em Mão de Obra, e a estrutura de suporte era praticamente insignificante. Com o advento de ferramentas computacionais e uma sofisticação das estruturas organizacionais, a parcela atribuída a custos indiretos ganho peso relativo em relação aos custos diretos, e com isto, a imprecisão e subjetividade das apropriações tornou-se uma questão relevante. Assim surge a metodologia $\mathrm{ABC}$ (Activity Based Costing) que visa a apropriação dos custos indiretos baseando-se em relações de causalidade entre, primeiro, os recursos consumidos pela organização e as atividades que nela se desempenham, e logo, num segundo momento, entre as atividades e os objetos de custo [3]. Essas relações de causalidade se materializam na forma dos chamados direcionadores de primeiro e segundo estágio respectivamente. Através desses direcionadores, elementos centrais desta metodologia [14], representa-se como as atividades, e não mais os produtos, consomem os recursos que a empresa adquiriu, e logo, como essas atividades existem para "servir" aos objetos de custo. 
O modelo $\mathrm{ABC}$ é considerado também, como ferramenta estratégica, que permite a gestão da organização através do acompanhamento do comportamento dos custos das atividades, e principalmente dos direcionadores de custo [4]. O conceito de Gestão Baseada em Atividades (ABMActivity Based Management) levanta essas questões.

A metodologia $\mathrm{ABC}$ tem se mostrado adequada para o tratamento de alguns tipos de custos que, apesar de importantes dentro do contexto organizacional, não estavam sendo tratados de maneira apropriada e conveniente. Esse é o caso dos custos da qualidade [2], e mais recentemente o dos custos ambientais [5]. Através desse novo enfoque, os custos podem ser classificados segundo sua natureza, utilizando para isto o conjunto de atividades mapeadas numa dada organização. A agregação de informações relacionadas com a prevenção, avaliação e com as falhas, tanto internas como externas, pode alavancar o processo de melhoria continuada e a busca pelo cumprimento do objetivo de perda zero [7].

A segregação dos custos de natureza ambiental é fundamental para apurar informações elementares ao processo de gestão econômica da empresa. Por isso, a gestão ambiental tornou-se uma área estratégica, necessitando, portanto, como as demais áreas consideradas estratégicas (a produção, por exemplo), de um tratamento específico, tendo em a importância que adquiriu o controle ambiental, sua premência e o expansivo volume de recursos nele investidos [15]. Ainda segundo [15] as estratégias principais da empresa, nesta área, devem ser: reduzir ao mínimo possível, se não eliminar, a produção de resíduos poluentes; elevar ao máximo a produtividade com grau de qualidade ambiental crescente; manter sistemas de gerenciamento ambiental eficazes ao menor custo permitido. Já que mensurar e informar é preciso, e tendo em vista que, o controle custos refletirá o nível de falhas existentes e o volume de gastos necessários para eliminar e/ou reduzir estas falhas, seja na forma de investimentos de natureza permanente, ou de insumos consumidos no processo operacional [15].

Dados o elevado consumo de recursos exigido, a complexidade e descentralização da operacionalização do controle ambiental, todos os recursos consumidos para o controle e preservação ambiental devem ser apurados. Assim o gestor da área econômica, conforme estudo feito por [15], terá condições para informar o custo ambiental, o qual, comparado aos custos planejados, resultará em informação relativa ao nível de eficiência e eficácia da área sob sua responsabilidade, pois somados os custos destas atividades, representarão os custos do processo de controle, preservação e recuperação ambiental, informação esta que deverá ser detalhada por centros de custos e por produto. O sistema de acumulação dos custos ambientais poderá, ainda, estar sistematizado no sentido de segregar custos decorrentes das falhas do progresso operacional no que tange ao controle ambiental e obviamente incorporar as categorias de custos, de Prevenção e Custos Ambientais de Avaliação.

Uma menção especial merecem os custos de falhas externas que são chamados também de externalidades, posto que, devido principalmente à sua intangibilidade, dificilmente são incorporados aos custos considerados pelas organizações. Isto pode afetar enormemente a eficiência dos sistemas de cálculo e gestão de custos bem como avaliações econômicas realizadas em projetos de investimentos [17]. Os custos externos de falhas podem variar de empresa para empresa, entretanto diversos autores coincidem em que uma inadequada forma de identificar e acumular esses custos poderá distorcer a gestão total dos custos ambientais por parte da organização [11].

\section{METODOLOGIA}

O trabalho foi desenvolvido na área de Tratamento e Pintura de uma montadora de carrocerias do Estado de Rio Grande do Sul, onde são gerados efluentes provenientes dos banhos de tratamento superficiais. Estes efluentes são tratados em uma Estação de Tratamento de Efluentes (ETE) própria, localizada nas mesmas dependências da empresa. A ETE produz água tratada e lodo. A água tratada é reutilizada como insumo do mesmo processo de banhos superficiais, gerador dos mencionados efluentes, enquanto que o lodo é enviado para um aterro sanitário próximo à empresa.

Como o objetivo é estabelecer uma estrutura que permita o cálculo do custo do tratamento de efluentes gerados pelos banhos, optou-se por realizar este cálculo em duas etapas. Referindo-se à figura 2, inicialmente foi calculado o custo da água tratada na ETE. Na segunda etapa, com o cálculo do custo da água tratada já realizado, este custo é repassado, na forma de insumo, ao processo de tratamentos superficiais. Posteriormente, estes custos são repassados aos produtos que consomem das atividades de tratamento superficial.

Inicialmente foram mapeados, os processos relacionados ao tratamento dos efluentes e os processos geradores dos mencionados efluentes, os tratamentos superficiais. Paralelamente foram levantadas as despesas de natureza ambiental, categorizadas e quantificadas por tipo de despesa. Em seguida foi estabelecida a estrutura de custos 
para o caso do tratamento de efluentes, para posteriormente, definir uma estrutura de cálculo de custos do processo de tratamento de superfícies (banhos). Em função desse último cálculo é possível verificar o impacto que tem a geração de efluentes e seu tratamento no custo dos produtos que contribuem para a geração desses resíduos.

Esta estrutura de cálculo de custos foi realizada baseandose na metodologia de custos baseados em atividades, ou ABC.

\begin{tabular}{|c|c|c|}
\hline Insumos & $\begin{array}{l}\text { Tratamento } \\
\text { superficial }\end{array}$ & Peças Tratadas \\
\hline 1 & 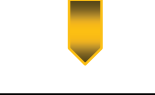 & \multirow{2}{*}{$\begin{array}{l}2^{\text {a }} \text { etapa de cálculo: } \\
\text { Cálculo do custo } \\
\text { ambiental ao tratar } \\
\text { peças }\end{array}$} \\
\hline & Resíduos & \\
\hline $\begin{array}{l}1^{\mathrm{a}} \text { etapa de } \\
\text { cálculo: Cálculo } \\
\text { do custo da água } \\
\text { tratada como } \\
\text { insumo }\end{array}$ & $\begin{array}{l}\text { Tratamento } \\
\text { de efluente }\end{array}$ & Insumos \\
\hline
\end{tabular}

Figura 2. Esquema dos processos e o cálculo dos custos em duas etapas.

\section{RESULTADOS}

Como foi mencionado na seção anterior, é inicialmente necessário o cálculo do custo da água tratada na Estação de Tratamento, para posteriormente, usar esse dado como valor do insumo no processo de tratamento superficial. Para tal se realizou o levantamento de despesas na estação de tratamento de efluentes. A tabela 1 mostra as despesas realizadas durante um mês pela empresa na ETE. Posteriormente procedeu-se ao cálculo do custo da água tratada utilizando como base os litros produzidos no mesmo mês (800 1). A tabela 2 mostra esta informação. Observe que na última coluna da tabela 2 se encontram os custos da água tratada por 1 e do lodo gerado por $\mathrm{kg}$ ao mês, sendo que este último apenas incorpora, para simplificação, o custo do seu transporte. Este lodo, como já foi comentado, é enviado para um aterro, com custo, considerando o transporte, de $\mathrm{R} \$ 0,05 / \mathrm{kg}$.

Posteriormente procede-se ao calculo do custo do processo de tratamentos superficiais. Para tal, levantaram-se as despesas realizadas no mesmo período com os banhos de tratamento (tabela 3). Neste levantamento já foi considerado o custo da água tratada na ETE como um insumo do processo, valor calculado na primeira fase do procedimento.
Tabela 1. Despesas realizadas na Estação de Tratamentode Efluentes (ETE) no período em análise.

\begin{tabular}{|l|r|r|r|}
\hline \multicolumn{1}{|c|}{ INSUMOS } & $\begin{array}{r}\text { Quant. } \\
\text { Utilizada }\end{array}$ & $\begin{array}{c}\text { Valor } \\
\text { Unitário } \\
\text { (R\$) }\end{array}$ & $\begin{array}{c}\text { Valor Total } \\
\text { (R\$) }\end{array}$ \\
\hline Soda Pon. & $460,56 \mathrm{~kg}$ & $\mathrm{R} \$ 1,35$ & $\mathrm{R} \$ 621,76$ \\
\hline $\begin{array}{l}\text { Sulfato de alumínio } \\
\text { líquido }\end{array}$ & $\begin{array}{r}1.395,00 \\
\mathrm{~kg}\end{array}$ & $\mathrm{R} \$ 1,10$ & $\begin{array}{r}\mathrm{R} \$ \\
1.534,50\end{array}$ \\
\hline Cal Hidratada & $113,00 \mathrm{~kg}$ & $\mathrm{R} \$ 0,50$ & $\mathrm{R} \$ 56,50$ \\
\hline Aquafil 60AP & $726,00 \mathrm{~kg}$ & $\mathrm{R} \$ 1,32$ & $\mathrm{R} \$ 958,32$ \\
\hline ELETRICIDA DE & & & \\
\hline Bomba 1 & $232,00 \mathrm{kw}$ & $\mathrm{R} \$ 0,50$ & $\mathrm{R} \$ 116,00$ \\
\hline Bomba 2 & $6,15 \mathrm{kw}$ & $\mathrm{R} \$ 0,50$ & $\mathrm{R} \$ 3,08$ \\
\hline Bomba 3 & $120,00 \mathrm{kw}$ & $\mathrm{R} \$ 0,50$ & $\mathrm{R} \$ 40,00$ \\
\hline Bomba 4 & $232,00 \mathrm{kw}$ & $\mathrm{R} \$ 0,50$ & $\mathrm{R} \$ 60,00$ \\
\hline Exaustor & $352,00 \mathrm{kw}$ & $\mathrm{R} \$ 0,50$ & $\mathrm{R} \$ 116,00$ \\
\hline Exaustor $\$ 176,00$ \\
\hline MÃO DE OBRA & & & \\
\hline Operador (R\$) & $100 \%$ & $\mathrm{R} \$ 500,00$ & $\mathrm{R} \$ 500,00$ \\
\hline Engenheira Química (R\$) & $25 \%$ & $\mathrm{R} \$ 2.000,00$ & $\mathrm{R} \$ 400,00$ \\
\hline $\begin{array}{l}\text { TOTAL DE GASTOS } \\
\text { COM ETE (R\$) }\end{array}$ & $\mathrm{R} \$ 5.207,15$ & & \\
\hline
\end{tabular}

Tabela 2. Produção da Estação de Tratamento de Efluentes no período.

\begin{tabular}{|c|c|c|}
\hline Água tratada & $\mathbf{8 0 0 ~ I}$ & $\mathbf{R} \$ \mathbf{6 , 5 1}$ \\
\hline Lodo & $12.500 \mathrm{~kg}$ & $\mathrm{R} \$ 0.05$ \\
\hline
\end{tabular}

A tabela 4 mostra o resumo da produção da seção de tratamentos superficiais obtida para o período em análise. Para calcular o custo por tipo de produto relacionado aos processos de tratamento superficial, e de acordo com a metodologia de custeio baseado por atividades, procedeu-se ao mapeamento das atividades relativas ao processo. As atividades mapeadas podem ser observadas na figura 3.

A etapa de apropriação de custos às atividades consiste em apropriar os custos às atividades mapeadas. Para tal objetivo, foram preparadas planilhas para agrupar nas atividades, constituídas pelas etapas dos banhos de tratamento, as despesas realizadas pela empresa no período em análise. Na tabela 5 são mostrados os cálculos dos custos da atividade "Desengraxar". Por motivos de espaço não se mostram os cálculos dos custos das outras atividades. Na célula sombreada, no canto inferior direito, pode ser observado o custo total da atividade por direcionador para o período, isto é, o custo por quilograma 
de produto processado nessa atividade. Os direcionadores para cada um dos insumos utilizados em cada atividade (direcionadores de recursos) estão dispostos na segunda coluna de cada planilha, junto com a quantidade de cada direcionador consumida por cada atividade. No caso da Engenheira Química e do Operador dos Banhos, os custos da Mão de Obra Direta (remuneração mais encargos) foram rateados em função do tempo dedicado por essas pessoas a estas atividades. Esta informação foi obtida através da própria estimativa dos envolvidos.

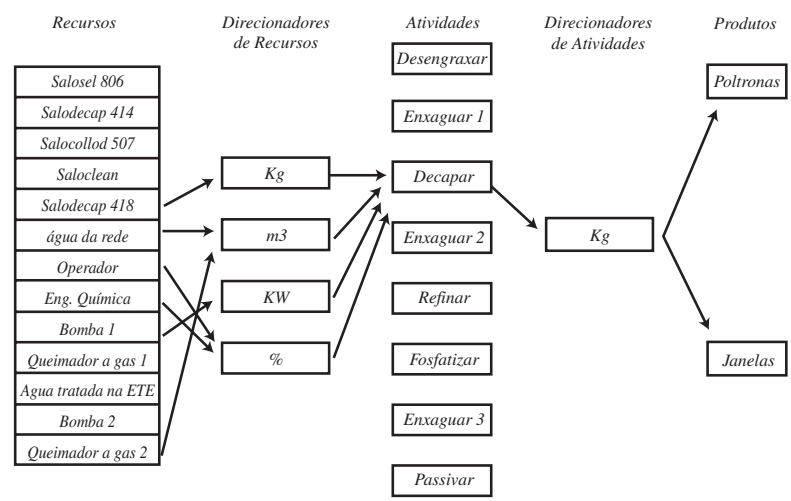

Figura 3. Mapeamento da metodologia utilizada.

Tabela 3. Despesas realizadas com os banhos de Tratamento Superficial.

\begin{tabular}{|c|c|c|c|}
\hline INSUMOS & $\begin{array}{l}\text { Quant. } \\
\text { Utilizada }\end{array}$ & $\begin{array}{c}\text { Valor } \\
\text { Unitário } \\
\text { (R\$) }\end{array}$ & $\begin{array}{l}\text { Valor Total } \\
\text { (R\$) }\end{array}$ \\
\hline Saloclean 605 & $100 \mathrm{~kg}$ & $\mathrm{R} \$ 3,14$ & $\mathrm{R} \$ 313,98$ \\
\hline Salodecap 418 & $700 \mathrm{~kg}$ & $\mathrm{R} \$ 0,95$ & $\mathrm{R} \$ 668,43$ \\
\hline Salocollod 507 & $150 \mathrm{~kg}$ & $\mathrm{R} \$ 3,35$ & $\mathrm{R} \$ 503,22$ \\
\hline Salodecap 414 & $700 \mathrm{~kg}$ & $\mathrm{R} \$ 0,96$ & $\mathrm{R} \$ 669,41$ \\
\hline Salosel 806 & $50 \mathrm{~kg}$ & $\mathrm{R} \$ 7,39$ & $\mathrm{R} \$ 369,57$ \\
\hline \begin{tabular}{|l} 
Água da rede \\
(CORSAN)
\end{tabular} & $50 \mathrm{~m}^{3}$ & $\mathrm{R} \$ 3,81$ & $\mathrm{R} \$ 190,50$ \\
\hline Água da ETE & $132 \mathrm{~m}^{3}$ & $\mathrm{R} \$ 6,51$ & $\mathrm{R} \$ 859,18$ \\
\hline \multicolumn{4}{|l|}{ MÃO DE OBRA } \\
\hline Operador & & & $\mathrm{R} \$ 400,00$ \\
\hline Engenheira Química & & & $\mathrm{R} \$ 400,00$ \\
\hline \multicolumn{4}{|l|}{ ELETRICIDADE } \\
\hline Bomba 1 & $88,00 \mathrm{kw}$ & $\mathrm{R} \$ 0,50$ & $\mathrm{R} \$ 44,00$ \\
\hline Bomba 2 & $88,00 \mathrm{kw}$ & $\mathrm{R} \$ 0,50$ & $\mathrm{R} \$ 44,00$ \\
\hline \multicolumn{4}{|l|}{ CONSUMO DE GLP } \\
\hline Queimador de gás 1 & $\begin{array}{r}2.195,60 \mathrm{~m}^{3} / \\
\text { dia*20dias }\end{array}$ & $\mathrm{R} \$ 1,10$ & $\mathrm{R} \$ 2.415,16$ \\
\hline \multirow[t]{2}{*}{ Queimador de gás 2} & $\begin{array}{r}2.195,60 \mathrm{~m}^{3} / \\
\text { dia*20dias }\end{array}$ & $\mathrm{R} \$ 1,10$ & $\mathrm{R} \$ 2.415,16$ \\
\hline & \multicolumn{2}{|c|}{$\begin{array}{r}\text { TOTAL DE GASTOS } \\
\text { BANHOS (R\$) }\end{array}$} & $\mathrm{R} \$ 9.292,61$ \\
\hline
\end{tabular}

Tabela 4. Dados de Produção na seção de banhos de tratamento superficial.

\begin{tabular}{|c|c|c|c|}
\hline & unidades/mês & $\mathbf{k g} / \mathbf{u n i d a d e}$ & $\mathbf{k g} / \mathbf{m e ̂ s}$ \\
\hline Poltronas & 7084 & 20 & 141.680 \\
\hline Janelas & 1868 & 15 & 28.020 \\
\hline
\end{tabular}

A segunda etapa do método consiste em apropriar os custos das atividades aos produtos. Para tal se faz necessário identificar os direcionadores de atividades para cada uma das atividades. Como pode ser observado na figura 3, o único direcionador escolhido para apropriar os custos das atividades é a quantidade de quilogramas de produto que passam por cada uma das atividades do processo de tratamentos superficiais. Observa-se, na figura 4, que existem atividades que só atendem a um tipo de produtos, as poltronas, desta forma a totalidade do custo dessa atividade será apropriado ao produto poltrona. Conseqüentemente, basta dividir o custo da atividade pelo total de quilos processados por cada atividade para assim obter o custo unitário do direcionador. Posteriormente deve multiplicarse esse custo unitário pelo total de quilogramas de cada produto e assim obter o custo unitário do tratamento superficial para cada produto. Finalmente, é possível calcular o custo de um dado produto que tenha sido processado durante esse mês pela seção de tratamentos superficiais apenas multiplicando o seu peso pela somatória dos custos unitários das atividades. Os custos unitários referentes aos banhos superficiais calculados segundo a metodologia se mostram na figura 9.

Tabela 5. Planilha de cálculo dos custos das atividades do processo de tratamento superficial (continua).

\begin{tabular}{|c|c|c|c|c|}
\hline TANQUE 01 & \multicolumn{4}{|c|}{ ATIVIDADE: DESENGRAXAR } \\
\hline \multicolumn{5}{|l|}{ INSUMOS } \\
\hline Saloclean 605 & $\mathrm{~kg}$ & 100 & $\mathrm{R} \$ 3,14$ & $\mathrm{R} \$ 313,98$ \\
\hline $\begin{array}{l}\text { Água da rede } \\
\text { (CORSAN) }\end{array}$ & $\mathrm{m}^{3}$ & 1 & $\begin{array}{r}\mathrm{R} \$ \\
3,81\end{array}$ & $\mathrm{R} \$ 3,81$ \\
\hline \multicolumn{5}{|l|}{ MÃO DE OBRA } \\
\hline Operador & $\mathrm{R} \$$ & 400,00 & & $\mathrm{R} \$ 50,00$ \\
\hline Engenheira Química & $\mathrm{R} \$$ & 400,00 & & $\mathrm{R} \$ 50,00$ \\
\hline \multicolumn{5}{|l|}{ ELETRICIDADE } \\
\hline Bomba 1 & $\mathrm{kw}$ & 88,00 & $\begin{array}{r}\mathrm{R} \$ \\
0,50\end{array}$ & $\mathrm{R} \$ 11,00$ \\
\hline \multicolumn{5}{|l|}{ CONSUMO DE GLP } \\
\hline \multirow[t]{4}{*}{ Queimador de gás 1} & $\begin{array}{l}\mathrm{m}^{3} / \mathrm{dia}^{*} \\
20 \mathrm{dia}\end{array}$ & $2.195,60$ & $\mathrm{R} \$ 1,10$ & $\mathrm{R} \$ 1.207,58$ \\
\hline & \multicolumn{3}{|c|}{ TOTAL DA ATIVIDADE } & $\mathrm{R} \$ 1.636,37$ \\
\hline & \multicolumn{3}{|c|}{ TOTAL EM kg } & 8.952 \\
\hline & \multicolumn{3}{|c|}{ TOTAL DA ATIVIDADE/kg } & $\mathrm{R} \$ 0,18$ \\
\hline
\end{tabular}


POLTRONAS

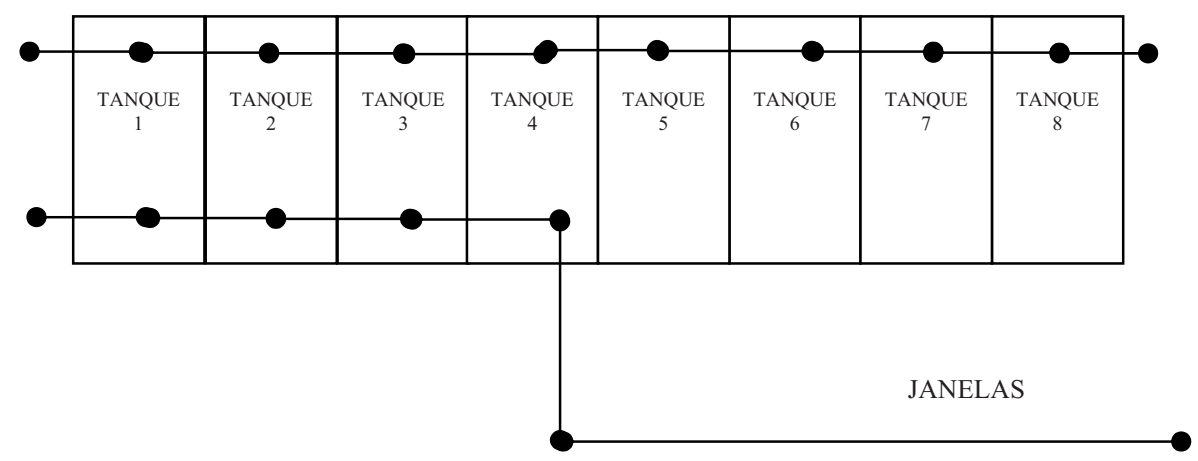

Figura 4. Mapa de Atividades para os produtos "Poltrona" e "Janela".

\section{IMPLANTAÇÃO DO SISTEMA COM UTILIZAÇÃO DE SOFTWARE}

Com o objetivo de melhorar o entendimento e esclarecer a aplicação do método, se mostra nesta seção a implantação desse sistema de cálculo dos custos da seção de tratamento de efluentes e tratamento superficial utilizando um software comercial. Nele foram usados três módulos, sendo que no primeiro são definidos os recursos consumidos pelo processo em análise. Na figura 5 podem ser vistos todos os recursos que foram considerados no caso estudado. Observe que os valores do período em análise também aparecem na coluna do extremo direito.

No segundo módulo foram descritos os processos através das atividades que os compõem. Na figura 6 são mostradas as atividades do processo "Tratamento de superfícies" consideradas no caso em estudo. O terceiro módulo permite a definição dos objetos de custos aos quais serão apropriados os custos das atividades. No caso deste estudo dois tipos de produtos, genéricos, com o intuito de simplificar o estudo, foram considerados, as "Poltronas" e as "Janelas". Esses dois produtos são os que passam pelos banhos de tratamento superficial e, portanto considerados neste estudo.

Feitas as definições dos recursos, ou custos indiretos, das atividades e dos objetos de custos, passou-se a definir os relacionamentos ou caminhos de alocação entre os recursos e as atividades, utilizando-se os direcionadores de primeiro estágio ou de recursos. Na figura 7 apresenta-se um exemplo de direcionamento entre o recurso "Engenheira Química" $\mathrm{e}$ as atividades nas quais ela desempenha tarefas. Observe também que no plano da esquerda são identificados os direcionadores para cada um dos recursos elencados, por exemplo, "kg", " $\mathrm{m}^{3} / \mathrm{dia}$ ", etc. No caso da "Engenheira química", o direcionador utilizado foi a percentagem do tempo que ela se dedica a cada uma das atividades, dado esse obtido através de depoimentos.

Da mesma forma, na segunda etapa de apropriação, são relacionadas as atividades com os objetos de custos. A figura 8 mostra a apropriação que, através dos direcionadores de segundo estágio, a operação "Passivar" tem em relação aos produtos ou objetos de custos.

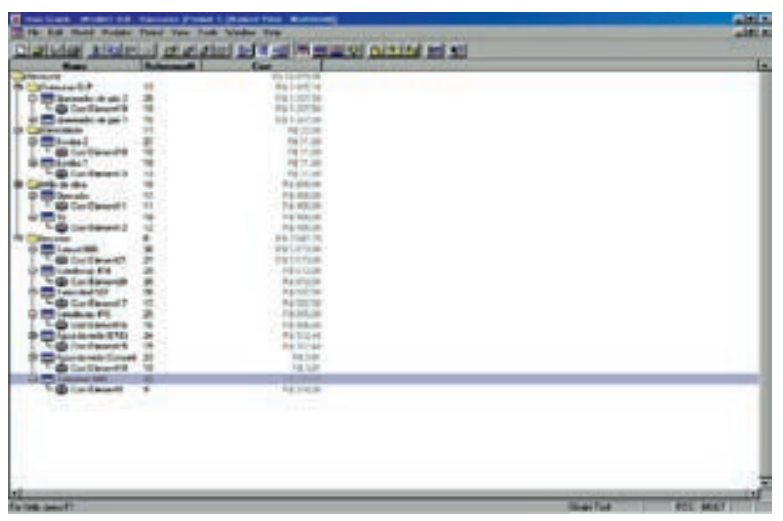

Figura 5. Módulo de Recursos.

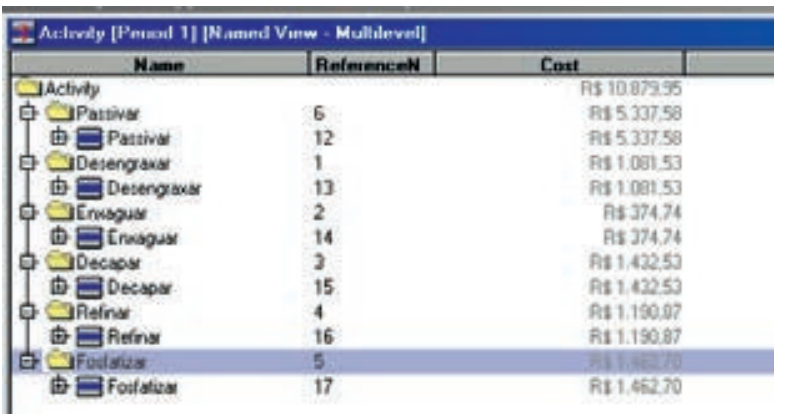

Figura 6. Módulo de Atividades. 


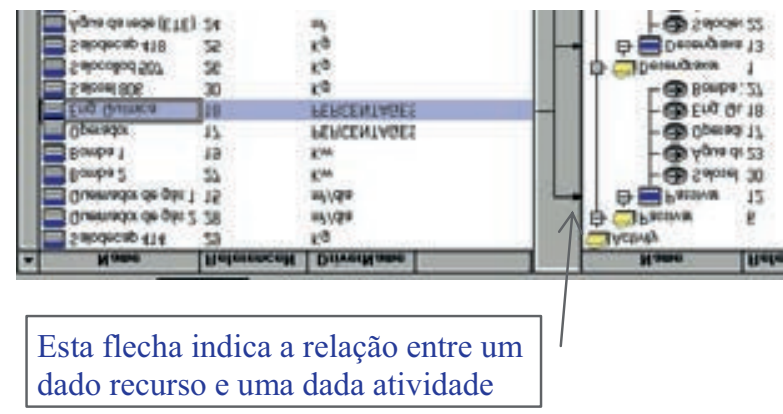

Figura 7. Caminhos de Apropriação dos Recursos para as Atividades.

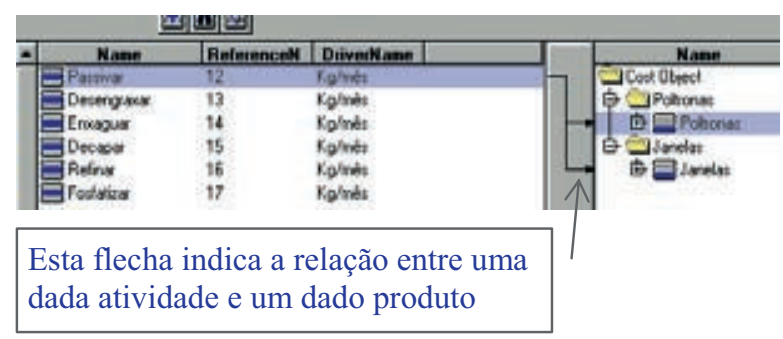

Figura 8. Caminhos de Apropriação dos Custos das Atividades para os Produtos.

Finalmente o sistema procede ao cálculo dos custos e fornece o custo unitário por atividade e por objeto de custo (figura 9).

\begin{tabular}{|c|c|c|c|}
\hline Name & BeferenceN & DriverQuanti & Custo Unitário \\
\hline \multicolumn{4}{|l|}{8 Cost Object } \\
\hline 追 GPoltronas & 5 & & \\
\hline 它罒 Poltronas & 4 & $141.680,00$ & $\mathrm{R} \$ 9,52$ \\
\hline$F \Leftrightarrow$ Passivar & 12 & $141.680,00$ & $\mathrm{R} \$ 4,46$ \\
\hline Desengraxar & 13 & $141.680,00$ & $\mathrm{R} \$ 0,90$ \\
\hline Enxaguar & 14 & $141.680,00$ & $\mathrm{R} \$ 0,31$ \\
\hline Decapar & 15 & $141.680,00$ & $\mathrm{R} \$ 1,20$ \\
\hline Refinar & 16 & $141.680,00$ & $\mathrm{R} \$ 1,19$ \\
\hline Fosfatizar & 17 & $141.680,00$ & $\mathrm{R} \$ 1,46$ \\
\hline 由 fJanelas & 4 & & \\
\hline 白きJanelas & 5 & $28.020,00$ & $R \$ 13,58$ \\
\hline$-\Theta$ Desengraxar & 13 & $28.020,00$ & $\mathrm{R} \$ 1.79$ \\
\hline Enxaguar & 14 & $28.020,00$ & $\mathrm{R} \$ 0,62$ \\
\hline Decapar & 15 & $28.020,00$ & $\mathrm{R} \$ 2,37$ \\
\hline Passivar & 12 & $28.020,00$ & $\mathrm{R} \$ 8,81$ \\
\hline
\end{tabular}

Figura 9. Custos das Atividades e dos Objetos de Custos.

\section{CONCLUSÕES}

Concluímos este trabalho salientando inicialmente a importância de medir e apropriar corretamente os custos ambientais, de maneira a possibilitar a gestão das despesas e detritos gerados. Em segundo lugar, verifica-se que a metodologia baseada em atividades apresenta-se como uma ferramenta efetiva para a correta apropriação desses custos. Com isso, os administradores poderão encaminhar ações corretivas que levem à minimização dos detritos e as correspondentes despesas. Medir o impacto que essas despesas têm nos custos dos produtos levará aos administradores redobrar os esforços de minimização das despesas, concentrando-se no gerenciamento dos direcionadores de recursos e de atividades.

No caso apresentado, torna-se necessário completar a aplicação da metodologia através da incorporação de outros setores e despesas relacionadas com a gestão ambiental. Só assim será possível ter um panorama completo da gestão ambiental na organização e o efeito que isso tem no custo dos produtos. Ademais, devese salientar que os custos incorporados nesta análise consideram apenas os custos tangíveis. Uma aplicação completa e correta da gestão dos custos ambientais deveria, entretanto, incorporar da melhor forma custos externos (e/ou intangíveis), no intuito de "internalizar" certos passivos que uma atividade industrial poderá estar criando no decorrer do seu funcionamento. A dificuldade de mensurar estes custos não impede que seja feita uma análise exploratória que pelo menos liste os principais items nesta categoria. Assim podemos mencionar, custos relacionados com possíveis doenças, ou riscos de acidentes relacionados com os banhos superficiais, contaminações de solo, emanações de vapores e gases para a atmosfera. Porém ao entrar neste campo, não podemos desconsiderar a possibilidade de criar certos ativos ambientais paralelamente. Principalmente, os relacionados com os benefícios obteníveis através da melhoria de imagem da empresa, produto do chamado Marketing Verde e da obtenção em algum momento de certificação ambiental, o que pode abrir potenciais negócios e aceder a certos mercados mais exigentes nesta matéria.

Para aumentar o nível de precisão dos dados obtidos, seria necessário acrescentar maiores informações aos dados utilizados, principalmente no que tange às despesas realizadas na área de tratamento de efluentes. Neste trabalho não foram consideradas, por exemplo, despesas tais como depreciação do imobilizado, seguros, impostos territoriais, entre outras. Considerando estas despesas seria possível obter um valor mais preciso dos custos dos produtos do processo de tratamento superficial.

\section{REFERÊNCIAS}

[1] L.M. de S. Campos. "Um estudo para a definição e identificação dos custos da qualidade ambiental". 
Dissertação (Mestrado) Programa de PósGraduação em Engenharia de Produção, UFSC. Florianópolis, Brasil. 1996.

[2] S. Cogan. "Activity-Based Costing - ABC". 2a edição. Editora Pioneira. 1995.

[3] R. Cooper. "Five Steps to ABC System Design". Accountancy, pp. 78-81. November 1990.

[4] P. Drucker. "Activity based Management: reasons to Implement". August 1999. Available in: http:// www.activitybasedmgmt.com/Activity_Based_ Costing.htm

[5] O. Durán. "Midiendo el Impacto en el Costo de los Productos de las Actividades de Gestión Ambiental: una aplicación de los costos $\mathrm{ABC}$ en una ensambladora de Buses". VI Congreso Mundial de Management. Santiago, Chile. 2003.

[6] O. Durán, E.L. Radaelli. "Metodologia ABC: Implantação numa Microempresa. Gestão e Produção", pp. 118-135. Agosto 2000.

[7] O. Durán, J. Telles. “A Gestão Ambiental en Empresas do Ramo Metalmecânico do Planalto Gaúcho". Revista do Centro de Ciencias Exatas e Tecnológicas da Universidade do Vale do Rio dos Sinos. Vol. XIV N 25, pp. 43-48. 2003.

[8] EPA. "An Introduction to Environmental Accounting As A Business Management Tool: Key Concepts And Terms". EPA 742-R-95-001. 1995.

[9] C. Gonçalves Jr. e E. de O. Pamplona. "Sistema de Custos para Micro e Pequena Empresa - Uso de Planilha Eletrônica com Macros". VII Simpep. Bauru, SP. Novembro 2000.

[10] H.T. Johnson e R.S. Kaplan. "Relevance Lost: The Rise and Fall of Management Accounting". Boston, MA: Harvard Business School Press. 1987.
[11] S. Joshi. R. Krishnan, L. Lave. "Estimating the hidden costs of environmental regulation", Accounting Review Vol. $76 \mathrm{~N}^{\mathrm{o}}$ 2, pp. 171-198. Abril 2001.

[12] L.G.A. Mauad e E. de O. Pamplona. "O Custeio $\mathrm{ABC}$ em Empresas de Serviços: Avaliação dos Problemas da Implantação em uma Empresa de Pesquisa”. VIII Congresso Brasileiro de Custos. São Leopoldo, Rio Grande do Sul. Outubro de 2001.

[13] R.S. da Motta. "Natureza também tem seu preço". Rumos. Rio de Janeiro, pp. 12-14. Maio/junho 1991.

[14] E. de Pamplona. "Contribuição para a análise crítica do sistema de custos $\mathrm{ABC}$ através da avaliação de direcionadores de custos". São Paulo. Tese de doutorado em Administração Contábil e Financeira. Fundação Getúlio Vargas / EAESP. 1997.

[15] M. de S. Ribeiro. "O custeio por atividades aplicado ao tratamento contábil dos gastos de natureza ambiental". Caderno de Estudos FIPECAR. Volume $10 \mathrm{~N}^{\circ} 19$, pp. 82-91. Setembro/Dezembro 1998.

[16] M. de S. Ribeiro e A.D. Gratão. "Custos Ambientais - $\mathrm{O}$ caso das empresas distribuidoras de combustíveis". VII Congresso Brasileiro de Custos. Recife/PE. Julho/Agosto, 2000.

[17] I.F. Roths e L.L. Ambs. "Incorporating externalities into a full cost approach to electric power generation life-cycle costing". Energy. Vol. $29 \mathrm{~N}^{\circ}$ 12-15, pp. 2125-2144. October-December 2004.

[18] E.R. Silva, A.C. Bornia e E. de O. Pamplona. "Uso do Custeio Baseado em Atividades em uma Agência Bancaria". VIII Congresso Brasileiro de Custos. São Leopoldo, Rio Grande do Sul. Outubro de 2001. 